\title{
Implant- and tooth-supported removable partial dentures: a case report
}

\author{
Prótese parcial removível sobre implante e dentes: relato de caso clínico
}

\author{
Jéssyca Maria França de Oliveira MELO'1 (iD) $000000018777847 x$ \\ Eduardo de Farias BARBOSA ${ }^{1}$ iD 0000000229746522
}

\begin{abstract}
This study aimed to report treatment of a patient with Kennedy's class I maxillary and class II mandibular arch with removable partial dentures supported on an external hexagon ( $\mathrm{HE}$ ) anterior type implant of regular diameter fitted with an O'ring type of attachment. This clinical case reports the oral rehabilitation of a senile patient whose clinical examination revealed missing dentition in the upper and lower arches, attrition of the lower anterior teeth, caries, and motor impairment affecting hygiene, mastication, and esthetic functions. Due to few severely impaired teeth, the pre-prosthetic preparation included extractions and restorations, followed by the fabrication of upper and lower removable partial dentures supported by an HE-type implant. This study is important because it addresses the current challenges faced in the implementation of treatment involving removable partial dentures combined with implants, which is a topic that still needs long-term follow-up and research.
\end{abstract}

Indexing terms: Complete denture. Dental prostheses implant-supported. Prostheses and implants. Removable partial denture.

\section{RESUMO}

Este trabalho tem por objetivo relatar o tratamento reabilitador com próteses removíveis classe I de Kennedy superior e classe I/ de Kennedy inferior associada a um implante de diâmetro regular, do tipo hexágono externo (HE) superior anterior, com o sistema de encaixe do tipo O'ring. O presente trabalho, relata um caso clínico em reabilitação oral em um paciente senil no qual apresentava ao exame clínico ausências dentárias no arco superior e inferior, desgaste por atrição nos dentes anteriores inferiores, cáries e comprometimento motor, prejudicando a higienização, função mastigatória e estética. Em virtude do grau de comprometimento de alguns dentes, o preparo pré-protético foi realizado com exodontias, restaurações e, por fim, a confecção de próteses parciais removíveis inferior e superior conjugada com um implante do tipo HE. O presente estudo é importante porque aborda os desafios atuais da implantação da prótese parcial removível combinada com o implante, um tema que ainda necessita de pesquisas de acompanhamento a longo prazo.

Termos de indexação: Prótese total. Prótese dentária fixada por implante. Próteses e implantes. Prótese parcial removível.

\section{INTRODUCTION}

Although the advent of preventive dentistry has reduced the incidence of tooth loss, the number of individuals using some kind of prosthesis is still large. Approximately $73 \%$ of partially edentulous patients report missing molars and premolars, and 40\% have arches classified as Kennedy's class I [1].

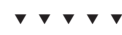

1 Universidade Federal de Pernambuco, Departamento de Prótese e Cirurgia Buco Maxilo Facial. Av. Prof. Moraes Rego, 1235, 50670-901, Cidade Universitária, Recife, PE, Brasil. Correspondence to: JMFO MELO. E-mail: <jessyca.fran@hotmail.com>.

$\checkmark v \mathbf{v}$

How to cite this article

MeRosa GC, Baldasso RP, Fernandes MM, Delwing F, Oliveira RN. Implant- and tooth-supported removable partial dentures: a case report. RGO, Rev Gaúch Odontol. 2020;68:e20200012. http://dx.doi.org/10.1590/1981-8637202000012201800005
} 
Various prosthetic treatment options are available for partial edentulism, including fixed partial prostheses (FPP), implants, or removable partial dentures (RPDs). The RPDs are most commonly used in clinical practice because they are economical, and facilitate easy care of the remaining teeth [1]

From a clinical point of view, single or multiple RPDs do not just restore lost teeth, but also have certain advantages over other rehabilitative resources within the social and professional context. These include (1) cost benefit; (2) minimal wear of tooth structure; (3) easier maintenance as compared to other types of prostheses; (4) mechanically efficient solution in complicated situations; (5) lesser implementation time as compared to other types of prostheses; and (6) versatility [2].

However, RPDs may have limited retention and stability due to the double-support system. In case of an RPD with a free end (e.g., distal extension RPDs), these aspects could worsen because of the propensity of the prosthesis to rotate during masticatory function. The denture-users of Kennedy's class I and II categories could present problems such as pain, occlusal disharmony, or soft tissue injury under the denture base or connector due to displacement of the distal extension of the prosthesis [3].

The double-support system refers to the biological elements represented by the abutment teeth and residual ridge, and mechanical elements represented by prosthesis supports (occlusal or cingulares), inner surface of the acrylic saddle, and higher connectors exclusively in the maxillary arch. In this double-support system, the mechanical elements transmit the masticatory forces to the biological elements that neutralize them [4].

The biological substrate holder for RPDs consists of the alveolar bone, together with the periodontal ligament fibers of the abutment teeth and oral mucosa covering the residual alveolar ridge. The periodontal ligaments fulfill the function of converting compressive loads exerted on the tooth into tensile loads, which is considered biologically healthy in order to maintain the physiological integrity of the bone. During this process, one must consider the individual ability of each tooth to resist these forces, which are better tolerated biologically when directed along the long axis of the tooth [4].

The alveolar mucosa is not a suitable structure to withstand the occlusal loads due to its resiliency. The average underlying bone resorption is $0.5 \mathrm{~mm}$ during the first few months of use of the acrylic saddle RPD. The resiliency of the oral mucosa absorbs part of the masticatory forces, though the others are transmitted to the alveolar bone in the form of compression forces. This compressive action is considered biologically unfavorable for the maintenance of the residual alveolar bone integrity, and it could accelerate the resorption process if uncontrolled [4].

The dental-prosthesis-supporting mucus mostly appears at the free-end of the prosthesis (Kennedy's class I and II) i.e., in the absence of abutment teeth in the distal part of the edentulous region. However, this route of transmission of forces could also be present in large areas of Kennedy's class IV. The complexity of this two-way transmission of forces at the free-ends is better understood with the concept that displacement of the soft tissue is always higher than that observed in adjacent abutment teeth. The deformation of the oral mucosa ranges from 0.4-3 $\mathrm{mm}$, and an average of $1.3 \mathrm{~mm}$ when the teeth have a physiological movement of around $0.1 \mathrm{~mm}$ [4].

Based on evidence that RPDs not only replace the lost structures, but also preserve and protect the remaining structures, much has been discussed about the advantages and disadvantages of RPDs, including its consolidation in rehabilitative therapy. However, there are still debates regarding its indications and combination with implants. Thus, with respect to current dental trends and the changes in recent decades, this case report presents a combination of conventional RPD and an implant-supported RPD, and discusses the different retention system.

\section{CASE REPORT}

A 70-year-old patient (H.S.X) of eastern origin, with chief complaint of functional and esthetic dental problems, presented to the Bauru Dental School, University of São Paulo for prosthetic treatment.

Besides the several missing teeth, history recording revealed dissatisfaction due to poor quality of life associated with missing dentition. The first screening included medical history review, intraoral clinical examination, and periapical radiography of the remaining teeth. The bone density was evaluated based on the panoramic radiograph.

In the case-planning phase, a patient model study was made from irreversible hydrocolloid impressions (Jeltrate, Dentsply). This helped in the analysis of occlusion, classification of the dental arches, and design in the 
surveyor. The upper arch was classified as Kennedy's class I, since only tooth number 13 and an osseointegrated

implant of the external hexagon (HE) type was present in the region of the 11 tooth. The lower arch was classified as Kennedy's class II modification 1, or unilateral posterior edentulism (figure 1).

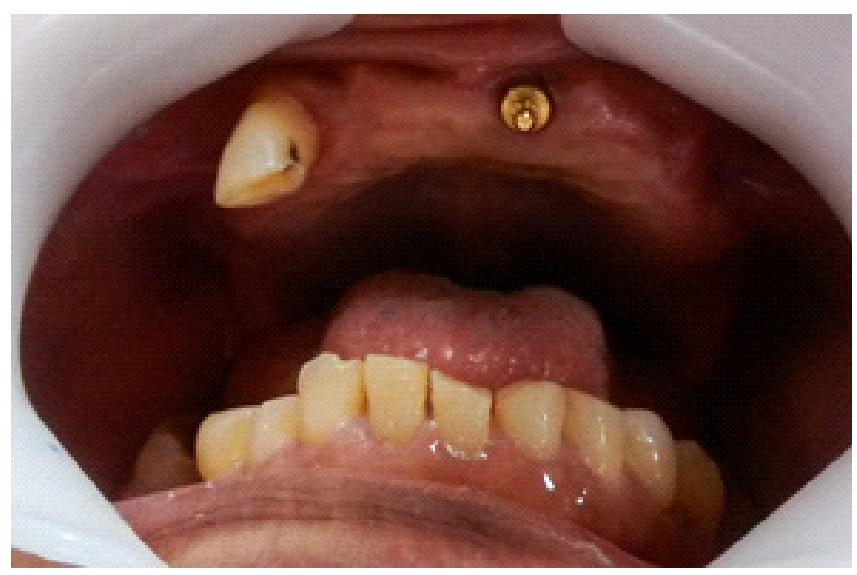

Figure 1. Clinical view.

The initial proposed treatment was preparing the oral environment, including prophylaxis, basic periodontal treatment, replacement of unsatisfactory dental restorations, and extraction of teeth condemned.

The patient had a broad upper prosthetic space that indicated less favorable prognosis. Due to financial constraints, the patient refused more implants in the upper arch. After deliberating the treatment options, and advantages and disadvantages, it was decided that mucus-tooth-implantsupported RPD retained with the upper O-ring type restraint and lower partial dentures retained with the staple would be the treatment of choice (figure 2 and 3 ).

After suitable preparation of the oral cavity, the insertion path was planned and defined the teeth the guiding plane. Niches were prepared for additional retention in composite resin to improve the stability of the RPD. The incisal surfaces of the lower anterior teeth that had physiologically worn out over the years were rebuilt.

After preparation in the mouth was completed, an irreversible hydrocolloid (Jeltrate, Dentsply) impression of the lower arch was obtained in a stock tray. The impression of the upper arch was recorded using an individual acrylic resin tray (JET, Classical), followed by recording the

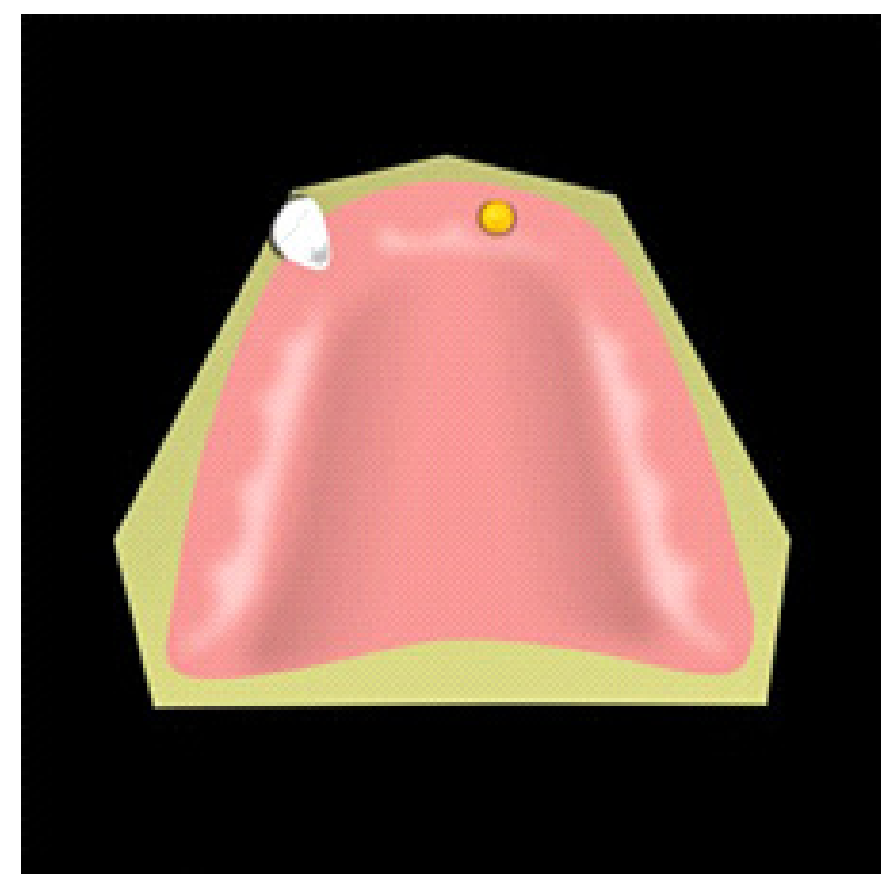

Figure 2. Upper arch after adjustments.

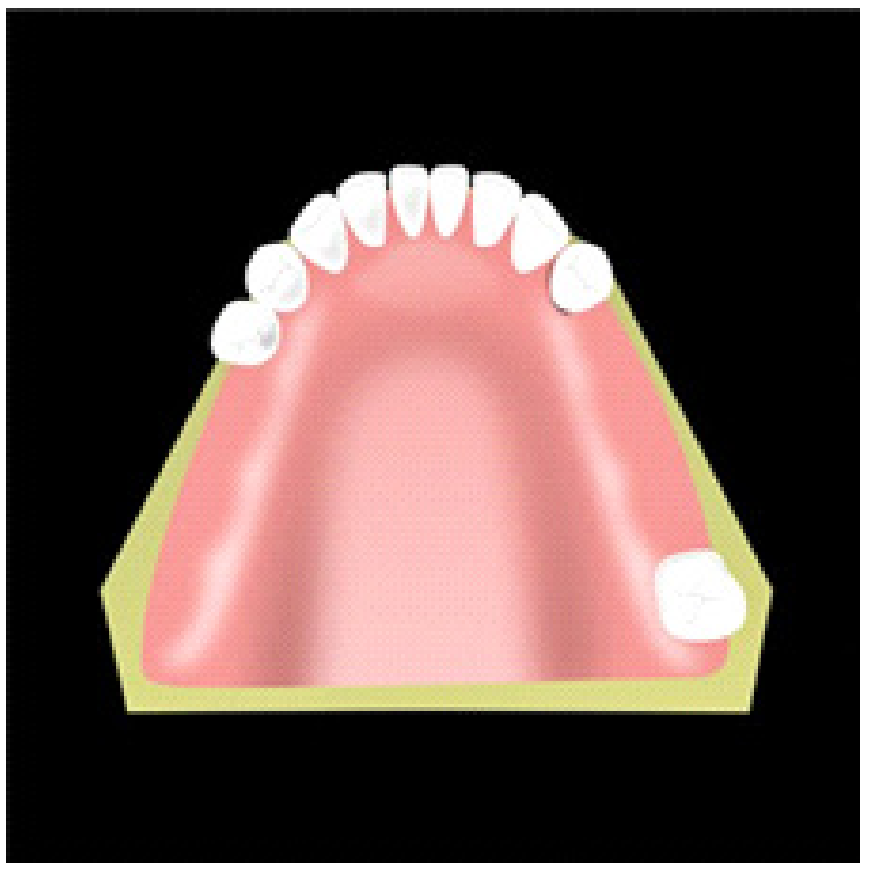

Figure 3. Lower arch after adjustments.

anatomical and functional impressions using the impression compound stick (Kerr) for peripheral sealing and mercaptan (Permlastic, Kerr) for functional impression around the edge. A reliable model was to be obtained based on the principles of complete denture prosthesis, because only one tooth and 
an implant in the upper arch provided auxiliary stability and retention to the RPD, and the retention characteristics of this RPD were based on the principles of adhesion, cohesion, and surface tension. The models were poured with type IV plaster (Durone, Dentsply).

The RPD structures were made of cobalt-chromium alloy (Co-Cr). In the upper RPD, palatal support was placed above the upper canine girdle (13), while the lower one derived mesial support from 44, 47, and 35 teeth and the distal part of 34 . The latter provided indirect retention in rotational movements.

T-stub action clasp was placed on teeth 13, 35, and 45. A circumferential clasp was designed for 47. The larger connector was used for total coverage of the palate with a lingual bar in the lower arch (figures 4 and 5).

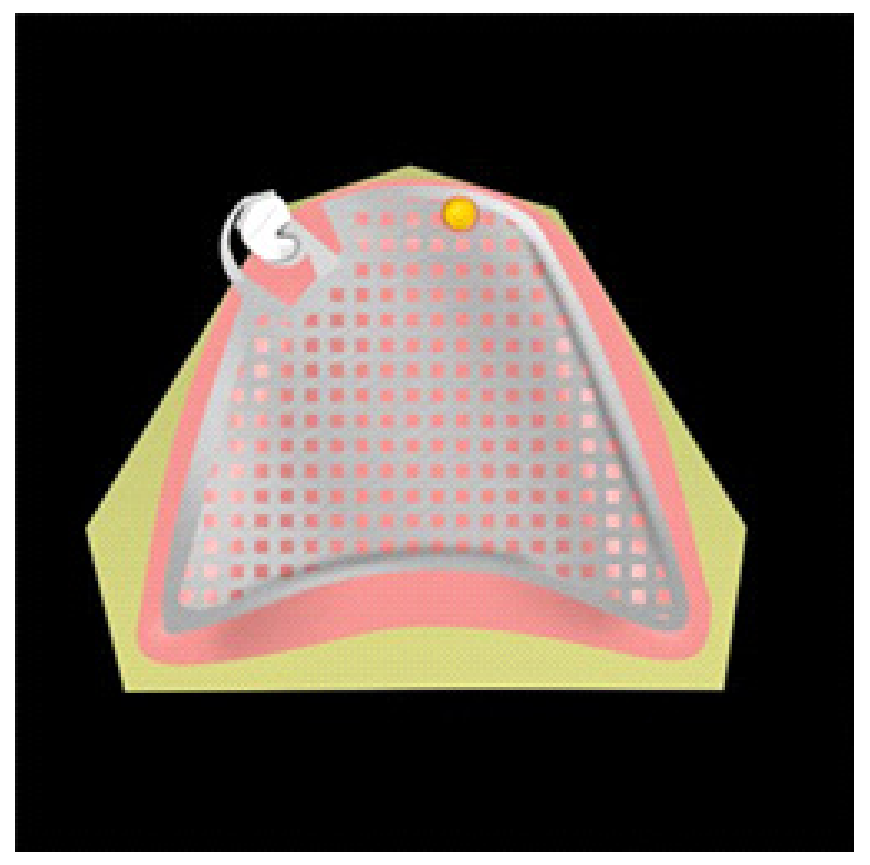

Figure 4. Planning of the upper arch.

The metal frames were tried in the patient's mouth in the next visit and the bases were made in acrylic resin on frames. Roller wax $n^{\circ} 7$ was positioned for testing. Initially, the upper wax-plane was adjusted. The prosthetic occlusal plane was determined with respect to the parallelism with the Camper's plane (line from the ala of the nose to the tragus) in the sagittal plane and the bipupillar line in the frontal plane. It is important to fit the upper wax-plane properly

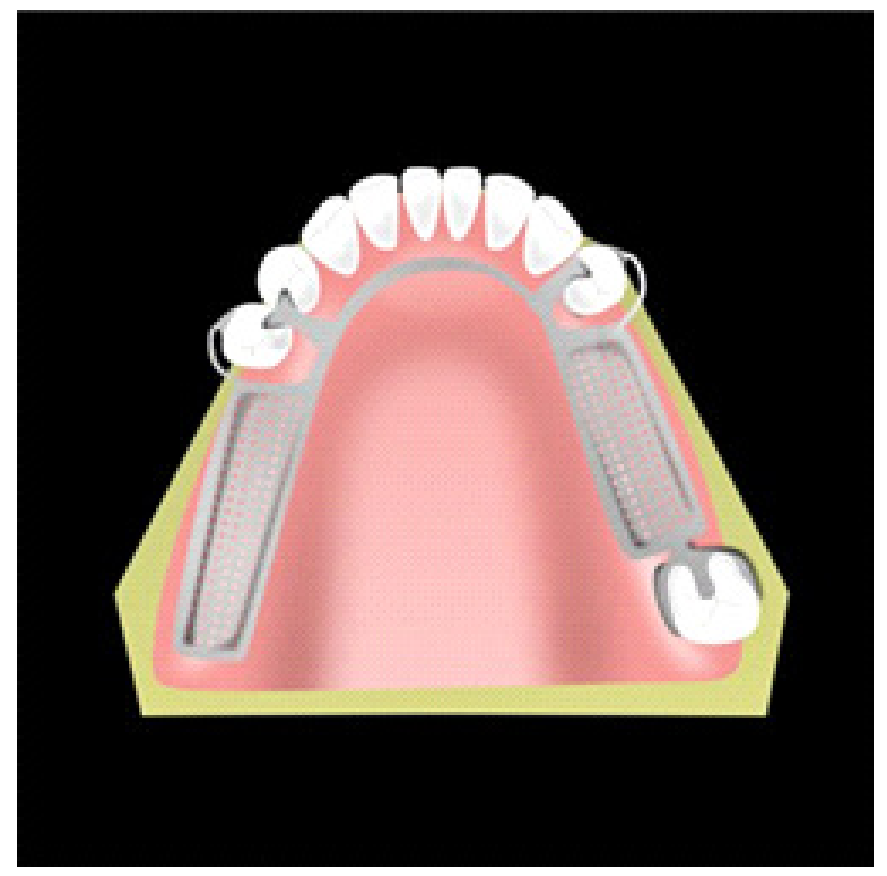

Figure 5. Planning of the lower arch.

in this phase for adequate support of the cheeks and lips and to evaluate the buccal corridor. The upper model was then transferred to the semi-adjustable articulator (ASA) (A7 Fix Articulator Standardized Bio-Art) using a face-bow (Arch Facial Elite, Bio Art). After the plaster was set, the lower model was mounted and the plane orientation of the bases was used to determine the intermaxillary occlusal vertical dimension (OVD) and central relation (CR). The reference lines, including the midline, grin line, and canine line, were drawn to assist in the selection and assembly of the teeth in wax. The teeth-set selected was 2A Trilux (T44-L3-M3 teeth). Sequentially, the lower arch model was fitted to the semi-adjustable surveyor ASA (A7 Fix Articulator Standardized Bio-Art).

In the following visit, the teeth setting and occlusion were checked along with esthetic and functional evaluation, and the color of the soft tissue was recorded (STG scale, color 14). In this phase, the patient provided informed consent for the work and authorized the prosthesis acrylization.

After a final proof of the artificial teeth mounted on the saddle RPD, the functional impression of the upper and lower mucosal support region was obtained. The impression was recorded with functional polyether (Impregum 3M, Espe) and sent to the laboratory for further work. It is of 
utmost importance that the functional mucosal impression of the support region be performed immediately after the final test of the artificial teeth mounted on the saddle RPD and prior to final casting in acrylic.

The implants were inserted and adjusted in the patient's mouth using the balanced bilateral occlusion scheme (figure 6).

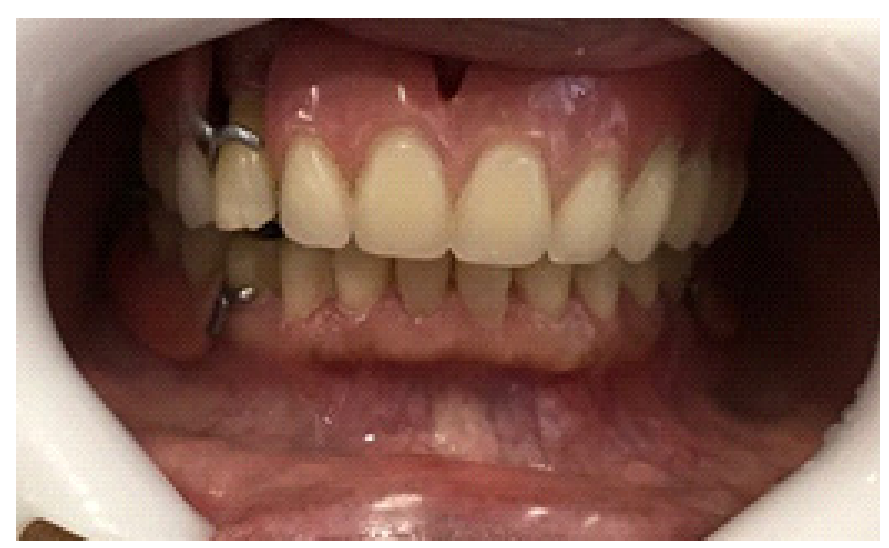

Figure 6. Insertion of removable prostheses.

After a month of the RPD and stomatognathic system functioning harmoniously, we proceeded to install the restraint system (O'ring). We used the HE-implant with mini-ball attachment, $3 \mathrm{~mm}$ in diameter, and $4.1 \mathrm{~mm}$ with O'ring mini-ball attachment cylinder (O'ring, Neodent). The torque used in the ball system accessories was $30 \mathrm{~N}$ according to manufacturer's instruction. Since the RPDs were in acrylic, the retention of the restraint system would need internal wear of the prosthesis for adaptation and installation of the mini-ball attachment. The protective disc was adapted to prevent flow of resin, and the O'ring was positioned such that the prosthesis could be tested to verify adjustment without interference. Following the placement of the intraoral component, chemically polymerizable acrylic resin (Duralay, Reliance) was to allow better seating on the implant. This was followed by the necessary finishing and final installation of the prosthesis (figure 9).

The patient was given guidelines to follow to ensure success and longevity of the prosthesis. First, the patient was oriented about the insertion and removal of the prosthesis along the long axis of the fittings in order to avoid lateral forces. The patient was also instructed about the importance of cleaning both the teeth and prostheses at necessary time intervals. The retention, cleaning and need for relining the dentures can be evaluated after six months.

\section{DISCUSSION}

Even with the current increase in influence of preventive dentistry, the number of individuals using prostheses is still large. This clinical case showed that it is possible to rehabilitate partially edentulous patients using an implant-supported RPD, which was capable of improving the stabilization of the prosthesis and maintaining the alveolar bone. It significantly improved the retention, comfort, mastication ability, esthetics, and phonetics as compared to conventional RPDs. These findings are supported by previous studies [1] reporting increased capacity and masticatory satisfaction in patients with implant-supported RPDs.

The mastication improved significantly and raised the quality of life levels. Studies in literature $[3,5]$ have described that although this type of prosthetic rehabilitation improved the magnitude of masticatory function, it did not completely restore the chewing capacity.

Baron et al. [6] observed that implants associated with the O'ring type of restraint system showed maximum stress values that were lower than other overdentures using the bar-clip system. Furthermore, the O'ring system also improved the distribution of stress when combined with the bar-clip system. The stress on the cortical bone in the region of the O'ring installation system in the upper RPD can be assessed only through monitoring.

Kono et al. [7] concluded that the placement of the implant in the distal edentulous ridge could prevent movement of the distal extension bases. The distribution under the base of the denture can be better controlled if the hand-ball system had more flexible connections, thus protecting the implant from harmful forces and improving prosthetic biomechanics. These aspects contributed to the necessary advantages in our case report.

Shahmiri et al. [8] observed that if the position of the mesial support was changed to the distal on the abutment tooth in an implant-supported RPD of Kennedy's class I, it would be susceptible to fracture at the acrylic resin-metal interface. This was because the metal diverted 
most of the tensile loads of the acrylic resin providing a better distribution than the acrylic resin-based denture. In the case presented, the support was placed on the mesial not only for the aforementioned reasons, but also for increased resistance required to avoid displacement of the prosthesis by oblique forces. The mesial support in this type of prosthesis will create a lever of the 2 nd kind. Therefore, when masticatory forces are imposed on the prosthesis, the retaining clip moves in the same direction as the force but opposite to that of the prosthetic equator and becomes passive. When a force tends to displace the prosthesis, the clamp is directed in the same direction, becoming active.

In a systematic review of the literature by Zancopé et al. [9], the authors found that there were high survival rates for RPDs associated with dental implants. Improved satisfaction and masticatory ability were reported without diminishing the implant-survival rates. However, clinical studies on the survival rate of the abutment teeth with comparable methods are still missing to define protocols for the use of the distal RPDs associated with implants. In the long term, prospective clinical trials are needed to understand which implant contributes to the increase in the survival rate of abutment teeth [9].

However, as noted in a study by Al Imam et al. [10], the two most frequent complications of RPDs were poor planning and inflammation of the oral mucosa, followed by less frequent fractures of staples. RPD treatment could improve the quality of life index related to oral health, but the RPD-related problems remained for a period of 1-5 years after treatment. Therefore, routine annual follow-ups are necessary in all cases without distinction [10].

By analyzing the Oral Health Impact Profile in 12 subjects, improvements were noted in all domains assessed for RPDs associated with the implants ball system, corroborating our procedure in this case [3].

According Hanif et al. [11], even with increased demand for implants in the dental market, several biological and mechanical complications do exist. However, despite the already well-researched, successful, evidence-based osseointegration concept, the association between implants and RPDs still requires longitudinal studies to prove their efficiency and long-term safety for wider use.

\section{CONCLUSION}

We can conclude from the presented clinical case that: - the upper implant-retained and supported RPD using the ball system resulted in stability and retention and hence, a better quality of life in the patient, because it allowed greater security during functional movements and satisfactory esthetics; - the conventional RPD in the lower arch was capable of optimum function and esthetics if properly planned and executed.

\section{Collaborators}

we participate in the design, writing and final approval of the published version of the work to make public our responsibility for its content, not omitting any links or financing agreements between authors and companies that may be interested in the publication of this article.

\section{REFERENCES}

1. Gonçalves TM, Campos CH, Garcia RC. Implant retention and support for distal extension partial removable dental prostheses: satisfaction outcomes. J Prosthet Dent. 2014;112(2):334-339. http://dx.doi.org/10.1016/j.prosdent. 2013.11.004

2. Neto AF, Carreiro AFP, Barbosa CMR. The issue of the removable partial denture in modern dentistry. Odontol ClínCient. 2011;10:125-128

3. Campos CH, Gonçalves TMSV, Garcia RCMR, Implantsupported removable partial denture improves the quality of life of patients with extreme tooth loss. Braz Dent J. 2015;26(5):463-467. https://doi.org/10.1590/0103-64402013 00097

4. Neppelenbroek $\mathrm{KH}$. Biomechanics of removable partial dentures. Pro-Dental Prosthesis. Upgrade Prog. 2010;2:39-139.

5. Gonçalves TM, Campos CH, Gonçalves GM, de Moraes M, Rodrigues Garcia RC. Mastication improvement after partial implant-supported prosthesis use. J Dent Res. 2013;92(12 Suppl):189S-94S. https://doi.org/10.1177/00220 34513508556.

6. Barão VA, Assunção WG, Tabata LF, Delben JA, Gomes EA, Sousa EAC, et al. Finite element analysis to compare complete denture and implant-retained overdentures with different attachment systems. J Craniofac Surg. 2009;20(4):1066-1071. https://doi.org/10.1097 / SCS.0b013e3181abb395

7. Kono K, Kurihara D, Suzuki Y, Ohkubo C. Pressure distribution of implant-supported removable partial dentures with stressbreaking attachments. J Prosthodont Res. 2014;58(2):115-120. https://doi.org/10.1016/j.jpor.2014.01.002

8. Shahmiri R, Das R, Aarts JM, Bennani V. Finite element analysis of an implant-assisted removable partial denture during bilateral loading: occlusal rests position. J Prosthet Dent. 2014;112(5):1126-1133. https://doi.org/10.1016/j.prosdent. 2014.04.023 
9. Zancopé K, Abrão GM, Karam FK, Neves FD. Placement of a distal implant to convert a mandibular removable Kennedy class I to an implant-supported partial removable Class III dental prosthesis: A systematic review. J Prosthet Dent. 2015;113(6):528-33.e3. https://doi.org/10.1016/j. prosdent. 2014.12.011

10. Al-Imam H, Özhayat EB, Benetti AR, Pedersen AM, Gotfredsen K. Oral health-related quality of life and complications after treatment with partial removable dental prosthesis. J Oral Rehabil. 2016;43(1):23-30. https://doi.org/10.1111/joor.12338
11. Hanif A, Qureshi S, Sheikh Z, Rashid H. Complications in implant dentistry. Eur J Dent. 2017;11(1):135-140. https:// doi.org/10.4103/ejd.ejd_340_16

Received on: 29/10/2018

Final version resubmitted on: 26/12/2018

Approved on: 28/2/2019 